\title{
Catalytic performances of chemically immobilized urease under static and dynamic conditions: A comparative study
}

\author{
Yilmaz Yurekli, Sacide Alsoy Altinkaya* \\ Department of Chemical Engineering, Izmir Institute of Technology, Gulbahce Kampusu, 35430 Urla, Izmir, Turkey
}

\section{A R T I C L E I N F O}

\section{Article history:}

Received 16 October 2010

Received in revised form 9 February 2011

Accepted 18 March 2011

Available online 27 March 2011

\section{Keywords:}

Covalent immobilization

EDC/NHS crosslinker

Membrane enzymatic reactor

Ultrafiltration

Urease

\begin{abstract}
A B S T R A C T
Immobilized urease has been used for direct removal of urea from aqueous solution and as biological sensing material in the preparation of urea biosensors. The former application is carried out under dynamic condition using ultrafiltration membrane either in tubular form or in flat sheet, while the latter is used in static condition. In this study, the performance of chemically immobilized urease on poly(acrylonitrileco-sodium methallyl sulfonate) ultrafiltration membrane was determined under both static and dynamic conditions. Results reveal that the immobilization enhanced the thermal and storage stabilities of urease. The hydraulic permeability of urea solution was not influenced by the addition of enzyme layer. The maximum reaction rate measured under pressure in the ultrafiltration unit was found higher compared to the rate observed just under mixing without any pressure applied. The highest urea conversion was found at the lowest transmembrane pressure and the urea concentration in the feed solution. The catalytic activity of the membrane was completely preserved at the end of 450 min of filtration.
\end{abstract}

(c) 2011 Elsevier B.V. All rights reserved.

\section{Introduction}

The removal of urea from aqueous solutions is an important problem in various industries ranging from chemical, biomedical to food industries. To prevent water pollution, urea content of fertilizer waste water effluents should be reduced to acceptable limits set by Environmental Protection Agency. Urea present in the alcoholic beverages needs to be eliminated to prevent formation of carcinogenic compounds [1]. During a typical hemodialysis operation, 100-300 L dialysate solution is used to remove toxic compounds, mainly urea, from blood. To reduce the cost of the treatment, regeneration of dialysate solution by removing urea is necessary [1]. For long term human space flights, recycling of wastewater which includes urea coming mainly from human urine is crucial. Commonly used approaches for the removal of urea are nonenzymatic urea hydrolysis which requires high temperatures and pressures and biological conversion of urea nitrogen to dinitrogen which suffers from instabilities of microbial bed. Hence, both methods have high operating costs [2]. Adsorption is not considered as an alternative removal method since urea does not show high affinity to common adsorbents [3]. Urea rejection by reverse osmosis membranes is also not efficient [4,5]. An attractive, alternative removal method is based on the hydrolysis of urea by urease immobilized on a suitable support material. Urease is

\footnotetext{
* Corresponding author.

E-mail address: sacidealsoy@iyte.edu.tr (S. Alsoy Altinkaya).
}

an enzyme widely occurring in nature and its presence has been detected in numerous organisms, including plants, bacteria, algae, fungi and invertebrates, and also in soils as a soil enzyme. Although urease has different protein structures, it catalyzes the hydrolysis of urea. Urea is quite stable in aqueous solutions with a half life of 3.6 years at $38^{\circ} \mathrm{C}$ [6]. Urease catalyzes hydrolysis of urea at a rate $10^{14}$ times faster than the uncatalysed one. Ureases play a prominent role in the overall nitrogen metabolism in nature. The active site of urease comprises dinickel centers which is responsible to decompose urea into final products carbonic acid and ammonia. The functional and practical properties of ureases with their important applications including medical, analytical, environmental and engineering approaches have been extensively reviewed in literature [7].

Numerous techniques have been developed for immobilizing enzymes onto micro or nano beads, hollow fibers, membranes and capsules. Among these techniques, enzyme immobilization within membrane pores or onto membrane surface has gained growing interest due to controllable transport of reaction substrates and products through the membrane. This is particularly important when the product acts as an inhibitor. Synthetic membranes have been preferred as enzyme carriers because of their low cost, easy surface modification, resistance to biodegradation and thermal and chemical stabilities. A detailed review of the studies over the last two decades on the immobilization of urease has been published by Krajewska [1]. In our work, polyacrylonitrile (PAN) based flat sheet membrane was used as the support since reactive groups can easily be generated on the surface through hydrolization reac- 


\begin{tabular}{|c|c|}
\hline \multicolumn{2}{|c|}{ Nomenclature } \\
\hline$D_{\mathrm{i}, \infty}$ & $\begin{array}{l}\text { Brownian diffusion coefficient of solute, } \mathrm{m}^{2} / \mathrm{s} \text {, } \\
1.48 \times 10^{-9}\end{array}$ \\
\hline$D_{\mathrm{eff}, i}$ & $\begin{array}{l}\text { effective diffusion coefficient of urea through } \\
\text { ith layer, } \mathrm{m}^{2} / \mathrm{s}, 1.09 \times 10^{-9} \text { for membrane and } \\
6.55 \times 10^{-10} \text { for enzyme layers. }\end{array}$ \\
\hline$K_{i, D}$ & $\begin{array}{l}\text { hindrance factor for diffusion of component } i \text {, } \\
\text { dimensionless, } 0.96\end{array}$ \\
\hline$K_{\mathrm{m}}$ & $\begin{array}{l}\text { substrate concentration at which the observed reac- } \\
\text { tion rate is half of } V_{\max }, \mathrm{kmol} / \mathrm{m}^{3}\end{array}$ \\
\hline$K_{0}$ & overall mass transfer coefficient, m/s, $2.71 \times 10^{-6}$ \\
\hline$k_{s}, k_{p}$ & $\begin{array}{l}\text { mass transfer coefficients for the feed and permeate } \\
\text { sides, } \mathrm{m} / \mathrm{s}, 1.04 \times 10^{-5} \text { for feed and } 3.97 \times 10^{-6} \text { for } \\
\text { permeate sides }\end{array}$ \\
\hline$k_{0}$ & adsorption rate constant, $\min ^{-1}$ \\
\hline$L_{\mathrm{enz}}$ & thickness of enzymatic layer, $\mathrm{m}, 50 \times 10^{-9}$ \\
\hline$L_{\text {mem }}$ & thickness of membrane layer, m, $25 \times 10^{-6}$ \\
\hline$M_{\mathrm{W}}$ & molecular weight of water, $\mathrm{kg} / \mathrm{kmol}, 18.02$ \\
\hline$r$ & radius of the stirred cell, $\mathrm{m}, 0.011$ \\
\hline $\operatorname{Re}$ & Reynolds number, dimensionless, 728 \\
\hline S & substrate concentration, $\mathrm{kmol} / \mathrm{m}^{3}$ \\
\hline Sc & Schmidt number, dimensionless, 606 \\
\hline $\mathrm{T}$ & temperature, $\mathrm{K}$ \\
\hline$V$ & reaction rate, $\mathrm{kmol} / \mathrm{m}^{2} \mathrm{~s}$ \\
\hline$V_{\max }$ & $\begin{array}{l}\text { maximum reaction rate possible if every enzyme } \\
\text { molecule is saturated with substrate, } \mathrm{kmol} / \mathrm{m}^{2} \mathrm{~s}\end{array}$ \\
\hline \multicolumn{2}{|c|}{ Greek symbols } \\
\hline$\alpha$ & $\begin{array}{l}\text { a constant which appears in Eq. (11), dimensionless, } \\
0.23\end{array}$ \\
\hline$\delta_{\mathrm{p}}$ & thickness of boundary layer, m, $3.73 \times 10^{-4}$ \\
\hline$\varepsilon_{i}$ & $\begin{array}{l}\text { porosity of ith layer, dimensionless, } 0.8 \text { for mem- } \\
\text { brane and } 0.48 \text { for enzyme }\end{array}$ \\
\hline$\Phi_{i}$ & $\begin{array}{l}\text { partition coefficient of component } i \text {, dimensionless, } \\
0.96\end{array}$ \\
\hline$\varphi$ & association factor, dimensionless \\
\hline$\lambda_{i}$ & effective solute to pore size ratio, dimensionless \\
\hline$\mu_{\mathrm{w}}$ & dynamic viscosity of water, $\mathrm{kg} / \mathrm{m} \mathrm{s}, 8.94 \times 10^{-4}$ \\
\hline$v$ & kinematic viscosity of water, $\mathrm{m}^{2} / \mathrm{s}, 8.97 \times 10^{-7}$ \\
\hline$v_{\mathrm{A}}$ & $\begin{array}{l}\text { molar volume of urea at its normal boiling point } \\
\text { temperature, } \mathrm{m}^{3} / \mathrm{kmol}, 0.058\end{array}$ \\
\hline$\rho_{i}$ & $\begin{array}{l}\text { density of component } i, \mathrm{~kg} / \mathrm{m}^{3}, 1170 \text { for membrane } \\
\text { and } 997 \text { for water }\end{array}$ \\
\hline$\Gamma_{\max }$ & maximum surface adsorbed amount, $\mu \mathrm{g} / \mathrm{cm}^{2}$ \\
\hline$\omega$ & stirring speed, rev/s \\
\hline
\end{tabular}

tion. Lin et al. [8] and Yang et al. [9] immobilized urease covalently onto outer surface of polyacrylonitrile (PAN) hollow fiber membrane using gluteraldehyde as a crosslinking agent. Authors have reported that the stability of immobilized urease to $\mathrm{pH}$ was higher than those of native counterpart and the former retained $86 \%$ of its initial activity after reusing 15 times. Furthermore, removal rate of urea from a dialyzer which consists of urease immobilized membrane was measured 2 times faster than the rate in a regular dialyzer. Godjevargova and Gabrovska [10] immobilized urease covalently onto poly(acrylonitrile-methylmethacrylatesodium vinylsulfonate) membranes subjected to seven different chemical modifications. The influences of modifications on $\mathrm{pH}$ optimum, water flow through the membrane, reaction rates, thermal inactivation and storage stabilities were investigated. Same group also immobilized urease onto PAN-chitosan composite membranes by first depositing chitosan onto PAN and then attaching urease covalently onto chitosan layer [11]. It has been found that the presence of amino groups facilitated the immobilization of urease onto the composite membrane. It is noted that in all of these studies glutaraldehyde was used as a cross linking agent, however, glutaraldehyde and its derivatives induce cytotoxic reactions during desorption [12]. In this study, we have used $\mathrm{N}$-ethyl- $\mathrm{N}^{\prime}$-(3-dimethylaminopropyl) carbodiimide hydrochloride (EDC) with N-hydroxysuccinimide (NHS) coupling agent as zero length crosslinker which is reported to be noncytotoxic in in vitro [13] and biocompatible in animal studies $[14,15]$. Urease in immobilized form are also used as biological sensing material for the fabrication of many types of urea sensors including amperometric [16,17], potentiometric $[18,19]$ and optical $[20,21]$. Those applications require characterization of urease immobilized membranes under static and dynamic conditions. In view of this fact, in this work, we focused on urease (URE) immobilization onto PAN based ultrafiltration membrane covalently using EDC/NHS crosslinking agents and characterized these membranes in terms of optimum $\mathrm{pH}$, temperature, kinetic parameters and storage stabilities under static conditions and in terms of transport properties and catalytic efficiencies under dynamic conditions.

\section{Materials and methods}

\subsection{Materials}

PAN based commercial flat sheet ultrafiltration membrane (AN69) with a molecular weight cut-off value of $30 \mathrm{kDa}$ supplied by Gambro, Hospal, France was used as a support material. It is produced by the copolymerization of acrylonitrile and sodium methallyl sulfonate. The sulfonate groups makes AN69 negatively charged membrane. We have measured the wet thickness of the membrane as $25 \mu \mathrm{m}$ and its pore radius from SEM images as $20 \pm 6 \mathrm{~nm}$ which was reported in reference [22]. The porosity of AN69 flat sheet ultrafiltration membrane was reported as 0.8 by Langsdorf and Zydney and we have used this value in the calculations [23]. Jack bean urease type III (EC 3.5.1.5 and U1500-20KU, 40 $\mathrm{U} / \mathrm{mg}$ solid) and Bradford reagent (B 6916) for the determination of protein amount were purchased from Sigma-Aldrich. EDC and NHS coupling agent were obtained from Sigma and Fluka, respectively. Urea and phosphate buffer were purchased from Fluka. Phenol (Rectabur $>99 \%$ ), sodium nitroprusside dihydrate (Fluka), sodium hydroxide anhydrous pellets (Carlo Erba $>97 \%$ ), sodium hypochlorite (Riedel, $6-14 \% \mathrm{Cl}$ active), sodium phosphate buffer solutions $\left(\mathrm{NaH}_{2} \mathrm{PO}_{4}, \mathrm{Na}_{2} \mathrm{HPO}_{4}\right)$ and acetic acid (Fluka) were purchased from different companies. All aqueous solutions were prepared with milli-Q water $(>18 \mathrm{M} \Omega \mathrm{cm})$.

\subsection{Methods}

\subsubsection{Fabrication of surface modified AN69 membrane}

The surface of $6 \times 6 \mathrm{~cm}^{2}$ AN69 membrane was hydrolyzed in $100 \mathrm{~mL}$ of aqueous solution containing $1 \mathrm{M} \mathrm{NaOH}$. The hydrolysis reaction took place on a shaker $(150 \mathrm{rpm})$ at $50^{\circ} \mathrm{C}$ for $20 \mathrm{~min}$. The membrane was then successively rinsed with water and then with $0.01 \mathrm{M}$ phosphate buffer solution at $\mathrm{pH}$ 5.5. During rinsing, the yellowish red color of hydrolyzed AN69 membrane was turned into white. As a result of chemical modification, cyanide $(-\mathrm{CN})$ groups on the membrane surface were partially converted into carboxylic $(-\mathrm{COOH})$ and amide $\left(-\mathrm{CONH}_{2}\right)$ groups and was designated as AN69A. Activation of the carboxylic groups was performed with EDC/NHS coupling agent. For this purpose, $3 \times 3 \mathrm{~cm}^{2}$ of AN69-A membrane was immersed in $10 \mathrm{~mL} 0.01 \mathrm{M}$ phosphate buffer solution at $\mathrm{pH}$ 5.5 containing predetermined amount of EDC/NHS and the solution was stirred at a rate of $100 \mathrm{rpm}$. In all activation steps, the 


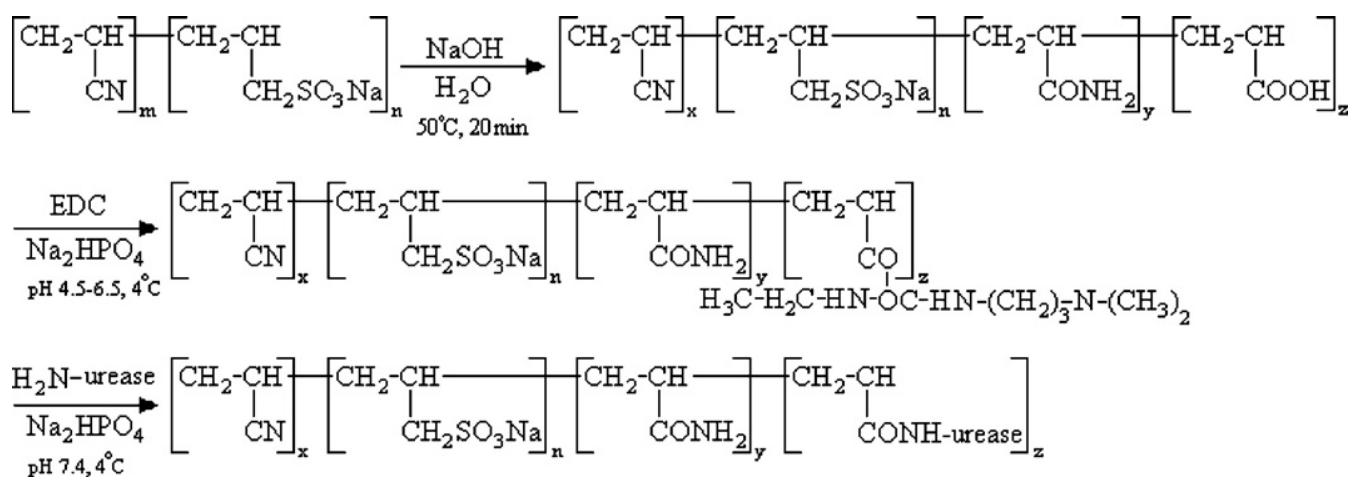

Fig. 1. Chemical reaction schemes for preparing urease immobilized AN69 membrane.

molar ratio of EDC/NHS was selected as 1:1. The activation temperature was set to a low value $\left(4^{\circ} \mathrm{C}\right)$ to prevent inactivation of EDC and side reaction. After the reaction was completed, the activated membrane was thoroughly rinsed with water and buffer at pH 7.4.

\subsubsection{Urease immobilization}

The EDC/NHS treated membrane was immersed in $10 \mathrm{~mL}$ of $0.01 \mathrm{M}$ buffer solution containing predetermined amount of urease at $\mathrm{pH} 7.4$ and $4{ }^{\circ} \mathrm{C}$ for predetermined time intervals. The reactions involved during hydrolysis, activation and urease immobilization are described in Fig. 1. After immobilization has been completed, the catalytic membrane was rinsed with water for 2 days.

Immobilization of urease was carried out as a function of the EDC amount (0-0.5 mM), activation time (1-24 h), urease amount $(0.002-0.07 \mathrm{mg} / \mathrm{mL})$, and immobilization time (1-24h).

\subsubsection{Determination of urease activity and bound protein}

Urease catalyzes the hydrolysis of urea to ammonium and carbon dioxide according to the reaction given below.

$2 \mathrm{NCONH}_{2}+\mathrm{H}_{2} \mathrm{O} \stackrel{\text { urease }}{\longrightarrow} 2 \mathrm{NH}_{3}+\mathrm{CO}_{2}$

The catalytic reaction for the native urease was started by introducing $0.5 \mathrm{~mL}$ of $34.7 \mu \mathrm{g} / \mathrm{mL}$ urease with $4.5 \mathrm{~mL}$ of urea solution. In the case of immobilized urease a small piece of urease immobilized membrane was immersed into $5 \mathrm{~mL}$ of $22 \mathrm{mM}$ buffer solution at $\mathrm{pH}$ value of 7.4 containing $10 \mathrm{mM}$ of urea. During the reaction, a shaker with a moderate speed $(100 \mathrm{rpm})$ was used and the temperature was maintained at $37^{\circ} \mathrm{C}$. During $30 \mathrm{~min}$ of time period, the concentration of ammonia formed was determined at different times and the results revealed that the ammonia production rates were linear, i.e. the activity was found independent of time. Based on this result, we have fixed the reaction time as $30 \mathrm{~min}$. At the end of $30 \mathrm{~min}$, reaction was stopped with $10 \%$ acetic acid solution. The activities of free and immobilized urease were estimated by determining the ammonia concentration formed during $30 \mathrm{~min}$ of reaction. The ammonia concentration was determined spectrophotometrically using Weatherburn method. In the method, in basic environment ( $\mathrm{pH}$ around 11) ammonia reacts with hypochlorite to form chloramine, which in the presence of nitroprusside as a catalyst, reacts with phenol, resulting in indophenol, a blue-coloured compound [24]. A $20 \mu \mathrm{L}$ of aliquots was added into a tube containing $5 \mathrm{~mL}$ of reagent-A ( $5 \mathrm{~g}$ of phenol with $25 \mathrm{mg}$ of sodium nitroprusside diluted to $500 \mathrm{~mL}$ with water). After shaking gently, $5 \mathrm{~mL}$ of reagent-B (2.5 g of sodium hydroxide and $4.2 \mathrm{~mL}$ of sodium hypochlorite diluted to $500 \mathrm{~mL}$ with water) was added. The mixture was then incubated at $37^{\circ} \mathrm{C}$ for $20 \mathrm{~min}$ and then the absorbance was read at $625 \mathrm{~nm}$ using a UV/VIS Spectrophotometer (Perkin Elmer, Model No: Lamda 45). The activity of urease was then defined as follows:

Specific Activity
$=\frac{\text { Number of moles of } \mathrm{NH}_{3} \text { produced in } 30 \mathrm{~min}}{30 \mathrm{~min} \mathrm{~cm}^{2}} \frac{1}{\Gamma_{\max }}$

The amount of protein bound to the membrane was determined by Bradford method [25]. During immobilization, $1 \mathrm{~mL}$ of sample was withdrawn from the urease solution at regular time intervals and mixed with $1 \mathrm{~mL}$ of Bradford reagent. The brilliant blue color resulting from the reaction was read at $595 \mathrm{~nm}$. The decrease in the amount of urease in solution was used to calculate the adsorbed amount onto the membrane surface.

\subsubsection{Determination of optimum $\mathrm{pH}$ and temperature}

The optimum $\mathrm{pH}$ and temperature of free and immobilized urease which correspond to highest activity were determined in the $\mathrm{pH}$ ranges between 5 and 9 and temperature range of $10-80^{\circ} \mathrm{C}$. The reactions were carried out in $22 \mathrm{mM}$ phosphate buffers, those for the temperature-activity dependence at pH 7.4.

\subsubsection{Determination of kinetic parameters}

The kinetic parameters of free and immobilized forms of urease were determined by measuring the rate of reaction $(\mathrm{V})$ with increased urea concentrations ([S]) from 1 to $100 \mathrm{mM}$. During measurements, $22 \mathrm{mM}$ buffer solution at $\mathrm{pH}$ of 7.4 was used. They were then obtained from the intercept $1 / V_{\max }$ and slope $\mathrm{K}_{\mathrm{m}} / V_{\max }$ of the Lineweaver and Burk plot which uses the inverse form of the Michaelis-Menten expression.

$\frac{1}{V}=\left(\frac{K_{m}}{V_{\max }}\right) \frac{1}{[\mathrm{~S}]}+\frac{1}{V_{\max }}$

\subsubsection{Determination of storage stabilities of free and immobilized urease}

Urease immobilized membranes and free urease were stored in water at $4{ }^{\circ} \mathrm{C}$. Their storage stabilities were determined by measuring the residual activities after a given time of storage.

\subsubsection{Filtration studies}

To characterize the performance of the catalytic membrane under dynamic condition, permeability experiments were performed using a dead-end stirred cell filtration system (Model 8010 , Millipore Corp, Bedford, MA) with a total internal volume of $10 \mathrm{~mL}$ and an active surface area of $4.1 \mathrm{~cm}^{2}$. The feed side pressure was maintained by nitrogen. To avoid concentration polarization, the feed solution was continuously stirred with a speed of $300 \mathrm{rpm}$. Filtrate samples were collected at several transmembrane pressures measuring the filtrate flux by means of an analytical balance (Sartorius BP221S with an accuracy of $0.1 \mathrm{mg}$ ) and in all permeation experiments system temperature was maintained at $23 \pm 2{ }^{\circ} \mathrm{C}$. 
Throughout the permeation experiments following protocol was applied. First, the commercial AN69 membrane was placed into the cell and compacted with water twice at 2 bars for $10 \mathrm{~min}$. After observing almost the same water permeation rates between those two compaction tests, filtration of water and then buffer was carried out at three different transmembrane pressures $(0.5$ bar, 1.0 bar and 1.5 bar). Buffer permeation rates were also measured through urease immobilized AN69 membrane. Finally, urea filtration experiments were conducted by varying urea concentration in the feed solution from 0.5 to $50 \mathrm{mM}$ at each transmembrane pressure. The concentration of urea in the samples obtained from retentate and permeate sides was determined at the end of $10 \mathrm{~min}$ filtrations.

\subsection{Theoretical}

\subsubsection{Enzyme adsorption kinetics}

During adsorption in static conditions, molecules first diffuse from the bulk solution to an area close to the membrane surface then transfer from this nearby position to the adsorbed state [26]. The adsorption process is considered diffusion controlled if step 1 is much slower then step 2, and reaction controlled if the opposite is true. In cases where electrostatic interactions and post-adsorption conformational changes are important, reaction controlled model has been proposed [27]. The model assumes that the concentration of the macromolecules in the bulk solution is uniform and the same as that at the liquid/solid interface. According to the model, there is a thin layer with a thickness of a few molecular diameters only, immediately adjacent to the surface. The reaction-controlled adsorption occurs within this layer and the rate of adsorption on the membrane surface is described by the following equation

$\frac{\mathrm{d} \Gamma}{\mathrm{d} t}=k_{1} C_{\mathrm{s}}\left(1-\frac{\Gamma}{\Gamma_{\max }}\right)$

In this equation, the term $\left(1-\Gamma / \Gamma_{\max }\right)$ accounts for the decrease in available membrane area and the surface concentration of the macromolecule $C_{\mathrm{s}}$ is equal to its bulk concentration $C_{\mathrm{s}}=C_{\mathrm{b}}$. If Eq. (4) is rearranged as

$\frac{\mathrm{d} \Gamma}{\mathrm{d} t}=k_{0}\left(\Gamma_{\max }-\Gamma\right)$

and integrated between $t=0$ and $t=t$; then

$\Gamma(t)=\Gamma_{\max }\left[1-e^{-k_{0} t}\right]$

where, $k_{0}=k_{1} C_{\mathrm{b}} / \Gamma_{\max }$

Eq. (6) was used to correlate urease adsorption kinetics with two fitting parameters, $\Gamma_{\max }$ and $k_{0}$.

\subsubsection{Effects of external mass transfer on immobilized enzyme kinetics}

The observed reaction kinetics of the immobilized enzyme can be influenced by the rate of substrate diffusion from the bulk to the external surface of the membrane. In cases where enzyme is immobilized only on the external surfaces of the membrane, mass transport from the bulk solution to the membrane surface and reaction at that position should be considered. At steady state, the average rate of the substrate transport from the bulk fluid to the membrane surface is balanced by the enzymatic reaction rate, therefore;

$k_{\mathrm{s}}\left(S_{0}-S_{\mathrm{s}}\right)=\frac{V_{\mathrm{max}} S_{\mathrm{s}}}{K_{\mathrm{m}}+S_{\mathrm{s}}}$

Here $S_{\mathrm{s}}$ and $S_{0}$ are the substrate concentrations at the interface and in the bulk fluid, respectively, and $k_{\mathrm{S}}$ is the mass transfer coeffi- cient of the substrate. Eq. (7) can be put in a dimensionless form as follows:

$\beta_{0}-\beta_{\mathrm{s}}=\frac{\lambda \beta_{\mathrm{s}}}{1+\beta_{\mathrm{s}}}$

where, $\beta_{0}=S_{0} / K_{\mathrm{m}}, \beta_{\mathrm{s}}=S_{\mathrm{s}} / K_{\mathrm{m}}, \lambda=V_{\max } / K_{\mathrm{m}} K_{\mathrm{s}}$

The influence of external mass transfer resistance on the overall enzymatic reaction is represented using the effectiveness factor $\eta$, which is defined physically by

Observed reaction rate

$\eta=\frac{\text { Rate which would be obtained with no mass transfer resistance, i.e, } S_{\mathrm{s}}=S_{0}}{}$

Mathematically $\eta$, is described by the following equation.

$\eta=\frac{V_{\max } S_{\mathrm{s}} / K_{\mathrm{m}}+S_{\mathrm{s}}}{V_{\max } S_{0} / K_{\mathrm{m}}+S_{0}}=\frac{\beta_{\mathrm{s}}\left(1+\beta_{0}\right)}{\beta_{0}\left(1+\beta_{s}\right)}$

$\beta_{\mathrm{s}}$ required in Eq. (9) can be calculated from Eq. (8) using measurable values of $\beta_{0}$ and $\lambda$. In Eq. (10) only the positive root will give the positive value of $\beta_{\mathrm{s}}$.

$\beta_{\mathrm{s}}=\frac{-\left(1+D_{\mathrm{a}}-\beta_{0}\right) \pm \sqrt{\left[\left(1+D_{\mathrm{a}}-\beta_{0}\right)^{2}+4 \beta_{0}\right]}}{2}$

The effectiveness factor can be calculated once $\lambda$ and $\beta_{0}$ are known. $\lambda$ value was evaluated using $V_{\max }$ and $K_{\mathrm{m}}$ values determined from the Linewear-Burk plot and the mass transfer coefficient calculated using the empirical correlation developed by Smith [28].

$\frac{k_{\mathrm{S}} r}{D_{i, \infty}}=\alpha R e^{0.567} \mathrm{Sc}^{0.33}$

The definitions of Re and Sc numbers are given below.

$\operatorname{Re}=\frac{\omega r^{2}}{v}$

$\mathrm{Sc}=\frac{\mu_{\mathrm{w}}}{\rho_{\mathrm{W}} D_{i, \infty}}$

The free diffusivity of urea was obtained from the empirical correlation of Wilke-Chang.

$D_{i, \infty}=\frac{117.3 \times 10^{-18}\left(\varphi M_{\mathrm{W}}\right)^{1 / 2} T}{\mu_{\mathrm{W}} v_{\mathrm{A}}^{0.6}}$

Here, in this equation the association factor $\varphi$, for water, viscosity of water, $\mu_{\mathrm{w}}$, and molar volume of urea, $v_{\mathrm{A}}$, were taken as $2.6,0.894 \times 10^{-4} \mathrm{cP}$ and $0.058 \mathrm{~m}^{3} / \mathrm{kmol}$, respectively $[29,30]$. The resulting urea diffusivity in water at $25^{\circ} \mathrm{C}$ was estimated as $1.48 \times 10^{-5} \mathrm{~cm}^{2} / \mathrm{s}$ which is comparable to the value reported as $1.38 \times 10^{-5} \mathrm{~cm}^{2} / \mathrm{s}$ in literature [31].

Under dynamic conditions, mass transfer resistances present during the transfer of the substrate from the feed side to the permeate side are shown in Fig. 2. The relative importance of the mass transfer compared to the enzymatic reaction is determined by a dimensionless number called Damköhler number $D_{\mathrm{a}}$. The Damköhler number can be interpreted as the ratio of the maximum reaction rate to the maximum mass transfer rate.

$D_{\mathrm{a}}=\frac{V_{\max }}{K_{0} S_{0}}$

If $D_{\mathrm{a}} \ll 1$, the maximum mass-transfer rate is much larger than the maximum rate of reaction and the process is said to be in the reaction-limited regime. On the other hand, when the masstransfer resistance is large, mass transfer is the limiting process and $\mathrm{Da} \gg 1 . K_{0}$ in Eq. (15) corresponds to the overall mass transfer 


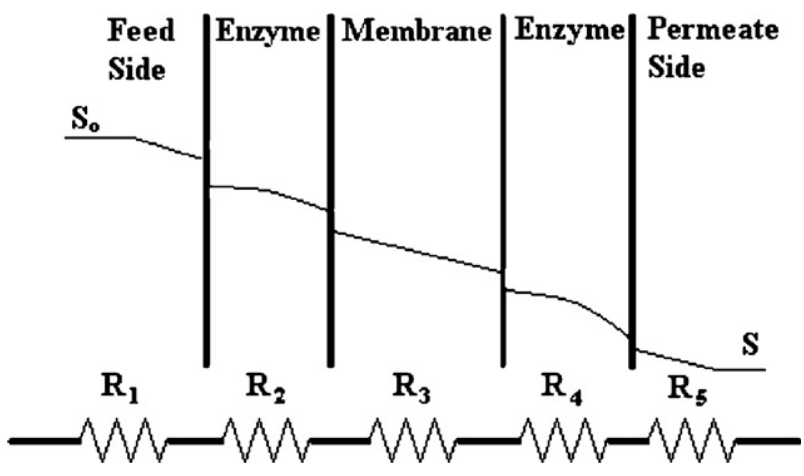

Fig. 2. The variation of substrate concentration through an enzymatic membrane under dynamic condition.

coefficient and it is obtained from the sum of all resistances shown in Fig. 2.

$$
\begin{aligned}
R_{T} & =R_{1}+R_{2}+R_{3}+R_{4}+R_{5} \\
& =\frac{1}{K_{0}}=\frac{1}{k_{\mathrm{s}}}+\frac{L_{\mathrm{enz}}}{D_{\mathrm{e}}}+\frac{L_{\mathrm{mem}}}{D_{\mathrm{m}}}+\frac{L_{\mathrm{enz}}}{D_{\mathrm{e}}}+\frac{1}{k_{\mathrm{p}}}
\end{aligned}
$$

In Eq. (16) the mass transfer coefficient on the feed side $k_{\mathrm{s}}$, was calculated from Eq. (11) and on the permeate side from the thickness of the boundary layer $\delta_{\mathrm{p}}$, and free solution diffusivity as follows;

$k_{\mathrm{p}}=\frac{D_{i, \infty}}{\delta_{\mathrm{p}}}$

The solute diffusivities (effective diffusivity) in the enzyme layers and in the membrane were calculated by multiplying the free solution diffusion coefficients with the partition coefficient, porosity and diffusive hindrance factor.

$D_{\text {eff }, i}=\varepsilon_{i} \Phi_{i} K_{i, D} D_{i, \infty}$

The solute diffusive hindrance factor, $K_{i, \mathrm{D}}$, is a function of the ratio between the solute and the pore diameters $\left(\lambda_{i}=d_{i, s} / d_{\mathrm{p}}\right)$ [32] and it was obtained using the expression below [33]:

$K_{i, \mathrm{D}}=1.0-2.30 \lambda_{i}+1.154 \lambda_{i}^{2}+0.224 \lambda_{i}^{3}$

\subsubsection{Activation energy of enzymatic reaction}

The activation energy or energy barrier of the reaction, $E_{\mathrm{a}}$ ( $\mathrm{kcal} / \mathrm{mol})$ may be different in free and immobilized form of an enzyme due to conformational changes occurred during immobilization. The activation energies of free and immobilized urease can be an indication of immobilization efficiency. The relationship between the rate of an enzymatic reaction, $V$, and the activation energy, $E_{\mathrm{a}}$, is given by the Arrhenius equation:

$\ln V=\ln A-\left(\frac{E_{a}}{R}\right)\left(\frac{1}{T}\right)$

The activation energy can be determined from the slope of $\ln V$ plotted as a function of $1 / T$.

\section{Results and discussion}

\subsection{Determination of optimal conditions for chemical modification of membranes}

The selection of appropriate $\mathrm{pH}$, buffer concentration, activation time and the concentration of EDC/NHS are important in minimizing detrimental effects during the activation of the membrane surface prior to immobilization. For this purpose, first, the activation of the carboxylic groups on the membrane surface with $\mathrm{EDC} / \mathrm{NHS}$ was carried out within the $\mathrm{pH}$ range from 4.5 to 6.5 and

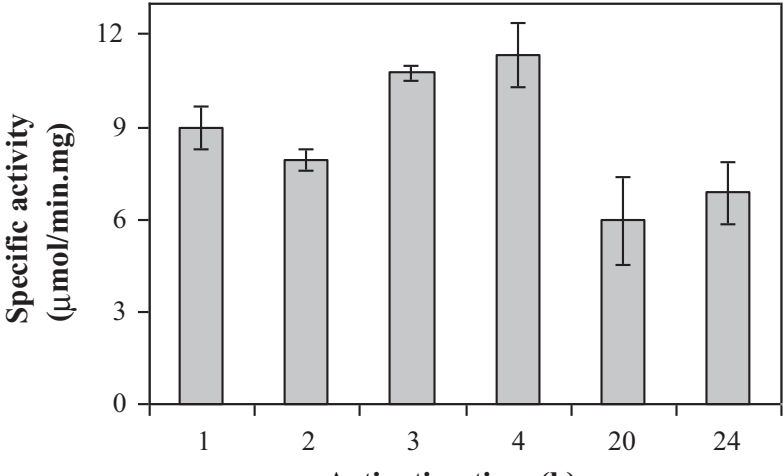

Activation time (h)

Fig. 3. The effect of activation time on the catalytic activity of immobilized ure ase. (The concentration of EDC and NHS are $0.05 \mathrm{M}$, the concentration of urease is $34.7 \mu \mathrm{g} / \mathrm{mL}$ and the immobilization time is $24 \mathrm{~h}$ ).

buffer concentration from 0.01 to $0.1 \mathrm{M}$. Then, urease immobilization was carried out under the conditions given in Section 2.2.2. The activity of the membrane prepared using EDC/NHS at pH 5.5 in $0.01 \mathrm{M}$ sodium phosphate buffer was found maximum (the results are not shown). The effect of activation time, which corresponds to the reaction time between the carboxylic groups on the membrane surface and the EDC/NHS coupling agent, on the catalytic performance of the membrane is shown in Fig. 3.

The activity was maximum when the membrane was activated for $3 \mathrm{~h}$. This represents the saturation of the surface functional groups (COO-) with EDC/NHS molecules. Beyond $4 \mathrm{~h}$, not only the reaction between EDC/NHS and the surface completed but also hydrolysis of EDC occurred which resulted in a reduced activity. $4 \mathrm{~h}$ of EDC/NHS activation have been reported in the literature $[12,34]$. Considering the standard deviations in the experimental data shown in Fig. 3, the activation time was chosen as $3 \mathrm{~h}$ for further studies. The lower activity at the first hour of immobilization might be assigned to the randomly distribution of urease molecules due to much more empty spaces available on the membrane surface. This might result in active site binding of urease molecules and hence, they become inactive. However, at a longer time, steric effects between urease molecules could be dominant that provide correct alignment of the urease molecules through multipoint attachment. A gradual increase in specific activity at $24 \mathrm{~h}$ of immobilization compared to that obtained at $20 \mathrm{~h}$ of immobilization could be explained by an $0.6 \mu \mathrm{g} / \mathrm{cm}^{2}$ increase in adsorbed amount of urease during last $4 \mathrm{~h}$ of immobilization.

Fig. 4 shows that the activity is increased nearly 4 times by increasing the concentration of EDC/NHS from 0 to $0.05 \mathrm{M}$ which

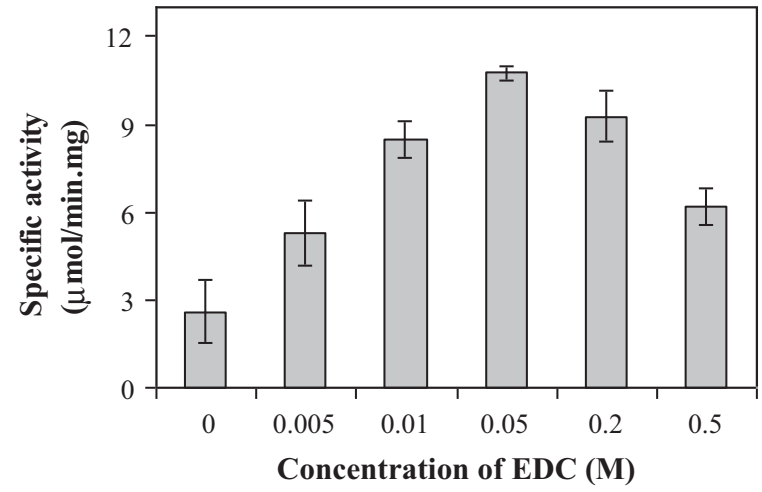

Fig. 4. The effect of EDC concentration on the activity of immobilized urease. (The concentration of urease is $34.7 \mu \mathrm{g} / \mathrm{mL}$, the activation and the immobilization times are 3 and $24 \mathrm{~h}$, respectively). 


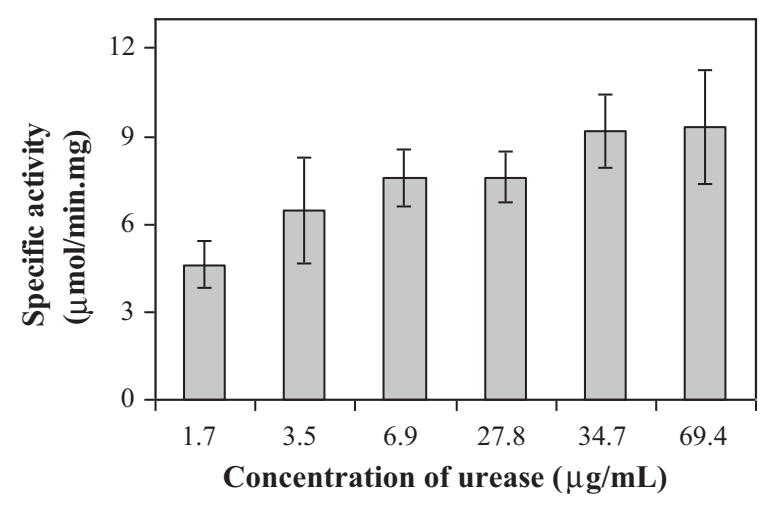

Fig. 5. The effect of urease concentration on the activity of immobilized urease. (The concentration of EDC and NHS are $0.05 \mathrm{M}$, the activation and the immobilization times are 3 and $24 \mathrm{~h}$, respectively).

represents the saturation concentration of the coupling agent. Further increase in EDC/NHS concentration resulted in reduced activities due to hydrolysis of EDC/NHS and possible inhibitory effect of the hydrolysis products on the urease activity.

Following the selection of best conditions for the activation of carboxylic groups on the surface of the membrane, the effects of two important parameters for the immobilization; the concentration of urease and immobilization time, were also investigated. Fig. 5 represents the change of urease activity with the concentration of urease in solution. The activity levels off to a plateau value for urease concentration of $34.7 \mu \mathrm{g} / \mathrm{mL}$. This value was used for further immobilization studies.

Fig. 6 shows the influence of immobilization time on the activity of catalytic membrane. The activity seemed to be stable beyond $2 \mathrm{~h}$ of immobilization, therefore, storage tests were performed with the catalytic membrane prepared with $2 \mathrm{~h}$ of urease immobilization. It was observed that the membrane lost all of its activity within 21 days of storage. The unstability of the membrane on which urease was immobilized within $2 \mathrm{~h}$ may originate from the insufficient reaction time. Although immobilization is a very rapid process, the multipoint interaction between non-complementary enzyme and support surfaces is a slow and time dependent process that may result in the difficulties in the correct alignment. A similar situation has been reported in reference [35] such that during desorption processes of 2 and $24 \mathrm{~h}$ immobilization, the amount of enzyme released was strongly reduced in the latter case. Considering fast activity lost during storage that we have observed and desorption of large amount of urease reported in the literature, we have selected urease immobilization time as $24 \mathrm{~h}$. This selection is in agreement with the other studies in literature [36-39].

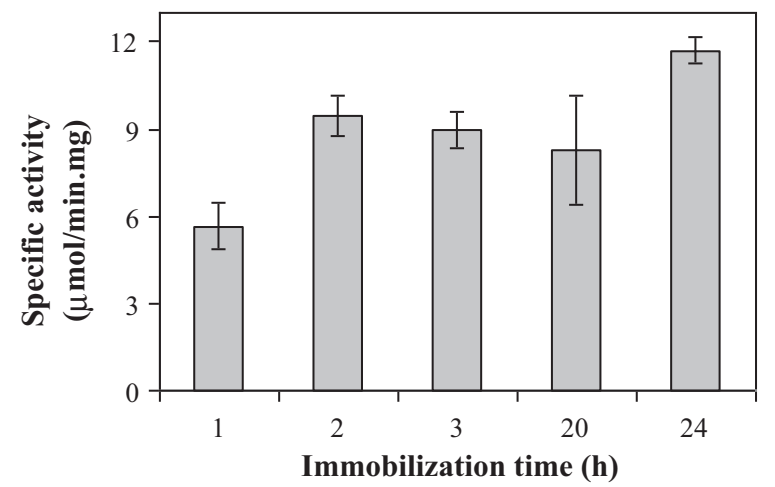

Fig. 6. The effect of immobilization time on the activity of immobilized urease. (The concentration of EDC and NHS are $0.05 \mathrm{M}$, the concentration of urease is $34.7 \mu \mathrm{g} / \mathrm{mL}$, and the activation time is $3 \mathrm{~h}$ ).

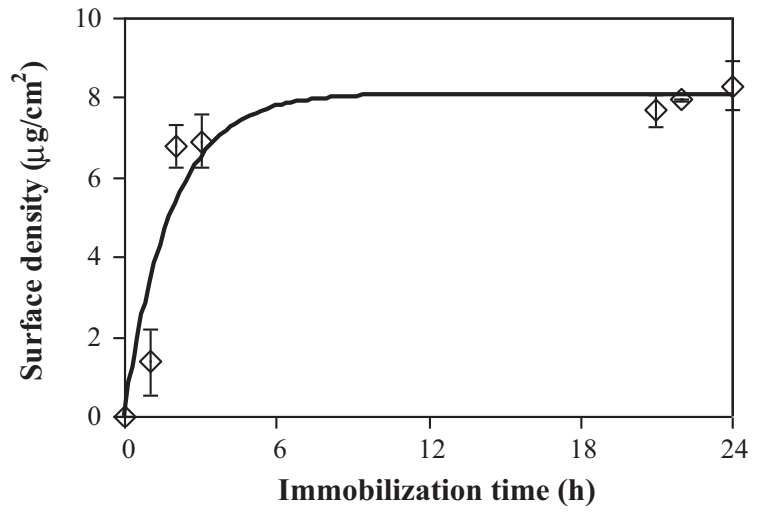

Fig. 7. Adsorption kinetics of urease immobilized onto activated AN69 membrane. Symbols represent experimental data and the line is the best fit using Eq. (6).

\subsection{Characterization results}

\subsubsection{Determination of the surface density}

During immobilization, $1 \mathrm{~mL} \times 3$ samples at predetermined time intervals were withdrawn from immobilization solution to follow the decrease in the amount of urease which corresponds to the amount adsorbed onto AN69 membrane. The adsorption kinetics of urease onto unit surface of activated AN69 membrane is represented in Fig. 7. A rapid adsorption occurred within $2 \mathrm{~h}$ of immobilization reaching ca. $62 \%$ of the maximum value. At the end of 1 day of immobilization, $8.3 \mu \mathrm{g}$ of urease was adsorbed on $1 \mathrm{~cm}^{2}$ of the membrane which is lower than the surface density of human serum albumin (HSA) on the EDC activated PAN membrane measured as $13.2 \mu \mathrm{g} / \mathrm{cm}^{2}$ [36]. The difference may be due to the smaller molecular weight of HSA and steric hindrance for urease. The static adsorption model represented by Equation 6 fits the kinetic data well. Using nonlinear least-square fit, the two model constants, $\Gamma_{\max }$ and $k_{0}$, were determined as $8.1 \mu \mathrm{g} / \mathrm{cm}^{2}$ and $9 \times 10^{-3} \mathrm{~min}^{-1}$, respectively.

\subsubsection{Determination of the $\mathrm{pH}$-activity curve}

$\mathrm{pH}$ is one of the important parameters capable of altering enzyme activities in aqueous solutions. Changes in $\mathrm{pH}$ may also alter the three dimensional conformation of the enzyme. The effect of $\mathrm{pH}$ on activity of the free and immobilized urease was investigated within the $\mathrm{pH}$ range of 5.0-9.0. As shown in Fig. 8, maximum activity was shifted from 7.4 to 7 when urease is in immobilized form. Relative activity on this plot is defined as the ratio of the activity obtained at certain $\mathrm{pH}$ to the highest activity measured within the $\mathrm{pH}$ range investigated. In literature, $\mathrm{pH}$ optimum for urease immobilized on different support membranes were reported in

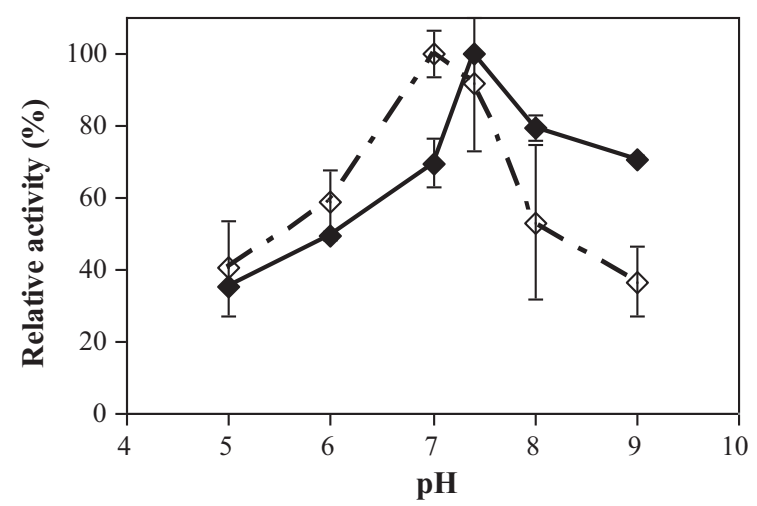

Fig. 8. pH-activity profiles of $(\diamond)$ native and $(\diamond)$ immobilized form of urease 


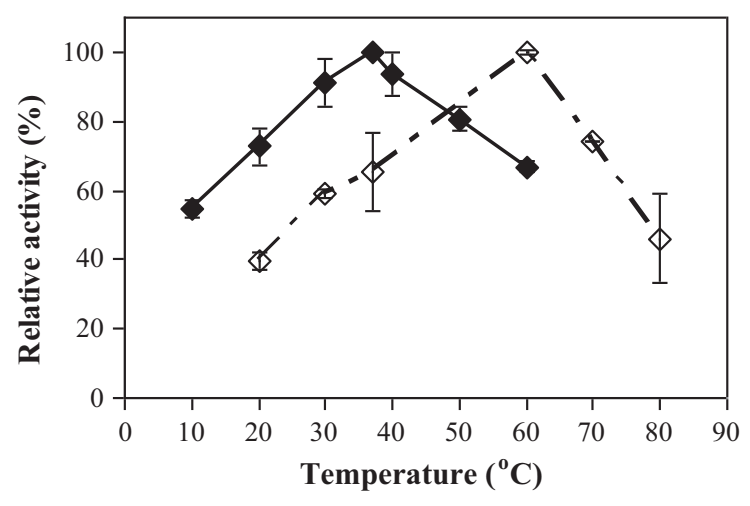

Fig. 9. Temperature-activity profiles of the native $(\diamond)$ and $(\diamond)$ immobilized form of urease.

the ranges between 5 and 8 in the detailed review by Krajewska [1]. As shown in Fig. 8, a variation in the optimum pH between the native and immobilized urease was obtained and the pH-activity curve of the latter was narrower which would be due to the difference in concentration of low molecular weight charged species between the microenvironment around the catalytic site and the bulk solution. In addition, the mass transfer limitation may influence the shape. The variation of the shape of the $\mathrm{pH}$-activity curves may also be attributed to $\mathrm{pH}$ changes in the domain of the immobilized urease particles, resulting from surface characteristics of the support and product accumulation. The magnitude of the $\mathrm{pH}$ shift compared to the native enzyme depends on the electrostatic potential of the support on which enzyme is immobilized. The change in $\mathrm{pH}$ shift or the shape of $\mathrm{pH}$-activity profile based on the electrostatic interactions between chitosan and the charges available on the urease is discussed by Krajewska and Piwowarska [40].

\subsubsection{Determination of the temperature-activity profile}

As a general rule, when an enzyme is immobilized on a support, it is thermally more stable than the native counterpart. The temperature dependence of the activities of the free and immobilized ureases was determined and they are illustrated in Fig. 9. For native urease, the optimum temperature was found to be $37^{\circ} \mathrm{C}$ whereas, it was shifted to $60^{\circ} \mathrm{C}$ for immobilized urease. Similar results have been reported for the immobilized urease on different supports with different immobilization methods [10,11,41]. The results in Fig. 9 indicate that the immobilization preserves the active nature of the enzyme at higher temperatures where the free urease is denatured. The activation energy $\left(E_{\mathrm{a}}\right)$ which corresponds to the critical threshold of energy to form an enzyme-substrate complex was determined as 3.96 and $4.62 \mathrm{kcal} / \mathrm{mol}$ for the free and immobilized ureases, respectively. The restricted movements of the urease in immobilized form and diffusion limitations during reaction occur and product release from the catalytic medium may cause an increase in activation energy. The activation energy of the enzyme may or may not change as a result of immobilization process. A detailed review by Krajewska [1] reports the activation energies of free and immobilized urease on various supports.

\subsubsection{Determination of the kinetic parameters of the immobilized urease}

The effect of immobilization on the kinetic properties of urease was also investigated by determining $V_{\max }$ and $K_{\mathrm{m}}$ values from the Lineweaver-Burk plots. From Fig. $10, V_{\max }$ and $K_{\mathrm{m}}$ values were determined as $12.42 \mu \mathrm{mol} / \mathrm{min} \mathrm{mg}$ and $7.55 \mathrm{mM}$ for immobilized urease. Corresponding values for free urease were found as $103 \mu \mathrm{mol} / \mathrm{min} \mathrm{mg}$ and $11.37 \mathrm{mM}$, respectively. One can explain the higher affinity of immobilized urease such that, the complex between immobilized urease and a substrate is formed easily [42].

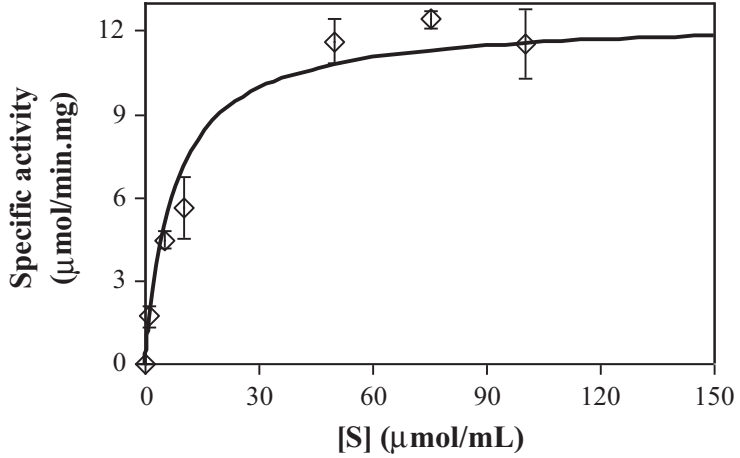

Fig. 10. Reaction rate of urease immobilized AN69 membrane as a function of substrate concentration.

Table 1

The change in effectiveness factors $\eta$, and Damköhler number $D_{\mathrm{a}}$ with respect to substrate concentration.

\begin{tabular}{cll}
\hline$[\mathrm{S}](\mathrm{mM})$ & $\eta$ & $D_{\mathrm{a}}$ \\
\hline 1 & 0.43 & 1.58 \\
8 & 0.95 & 0.20 \\
10 & 0.97 & 0.16 \\
50 & 1.00 & 0.03 \\
75 & 1.00 & 0.02 \\
100 & 1.00 & 0.02 \\
\hline
\end{tabular}

In addition, it may also an indication of conformational changes occurred during immobilization. The observed $V_{\max }$ was nearly 8 times lower in immobilized form than in the free form of urease since, during immobilization structural change of the enzyme may alter the affinity between the substrate and the enzyme and mass transfer limitation may reduce the rate. Similar $V_{\max }$ and $K_{\mathrm{m}}$ values for the free and immobilized urease on various supports were also reported in detailed review of Krajewska [1].

The influence of the external mass transfer effects on the measured reaction kinetics was determined by evaluating the Damköhler number and the effectiveness factor for each substrate concentration. The results tabulated in Table 1 clearly indicate that the external mass transfer effects are negligible for most of the substrate concentration range used for collecting kinetic data. These results confirm that the overall reaction rate is mainly controlled by the enzymatic reaction.

\subsubsection{Determination of the storage stabilities}

Fig. 11 represents the comparison of the retaining activities of free and immobilized ureases. The activity loss of the immobilized enzyme on storage was slower than that of the free enzyme, the

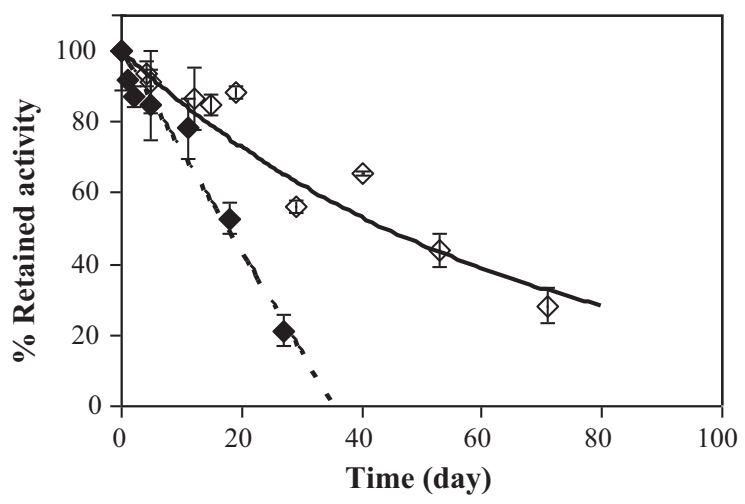

Fig. 11. Storage stabilities of $(\diamond)$ free and $(\diamond)$ immobilized form of urease. Symbols denote the experimental data and the lines are the best fit using Eqs. (21) and (22). 


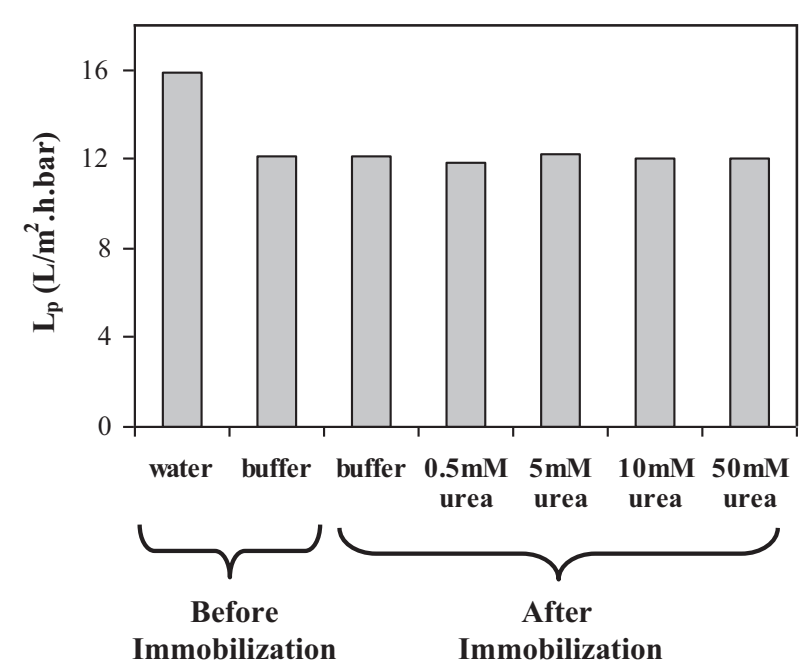

Fig. 12. Hydraulic permeabilities of water, buffer and urea solutions through modified AN69 membrane on which urease was chemically immobilized.

half-lives being 44 and 20 days, respectively. The higher stability is due to restricted movement of immobilized urease. A gradual decrease in activity was followed and $37 \%$ of its initial activity was still preserved at the end of 70 days of storage when urease was in immobilized form. The deactivation kinetics during storage tests for the immobilized and free forms of urease were correlated using exponential and linear models, respectively.

$\ln \left[\frac{V(t)}{V(0)}\right]=-k_{\mathrm{d}} t$

$V(t)=V(0)-k_{\mathrm{d}} t$

Based on these models, the deactivation rate constants $k_{\mathrm{d}}$, were estimated as $3.6 \times 10^{-5}$ and $8 \times 10^{-5} \mathrm{~min}^{-1}$ for the immobilized and native ureases, respectively. From the result, one can conclude that with the immobilization of urease, its deactivation rate is reduced nearly 2 times.

\subsection{Filtration results}

The performance of the prepared membranes under dynamic conditions was first determined by collecting hydraulic permeabilities. For this purpose, the volumetric flux of the urea solution filtrated was determined for each transmembrane pressure. Then, the slope of the plot of the volumetric flux vs transmembrane pressure yielded the hydraulic permeability of the solution, $L_{\mathrm{p}}$. Fig. 12 shows the hydraulic permeability of water, buffer and urea solutions through noncatalytic and catalytic AN69 membranes. Negligible difference was observed in the hydraulic permeabilities of buffer solution before and after urease immobilization. Although addition of a thin enzyme layer exerts a resistance to flow; this is compensated by the enhanced hydrophilicity of the membrane, hence, the hydraulic permeability value remains constant. It is also observed that the hydraulic permeability of urea solution is not influenced by the urea concentration in the feed. This is due to very small dissociating constant of urea, hence, its charge free nature and small size compared to the average pore size of the membrane. In addition, the result also indicates that, the stirring rate during filtration is enough to prevent concentration polarization.

The catalytic performance of the membranes under dynamic conditions was also tested by measuring the ammonia formation, hence, calculating the urea conversion as a function of feed concentration and the transmembrane pressure. The results are represented in Fig. 13. Conversion decreased both with the

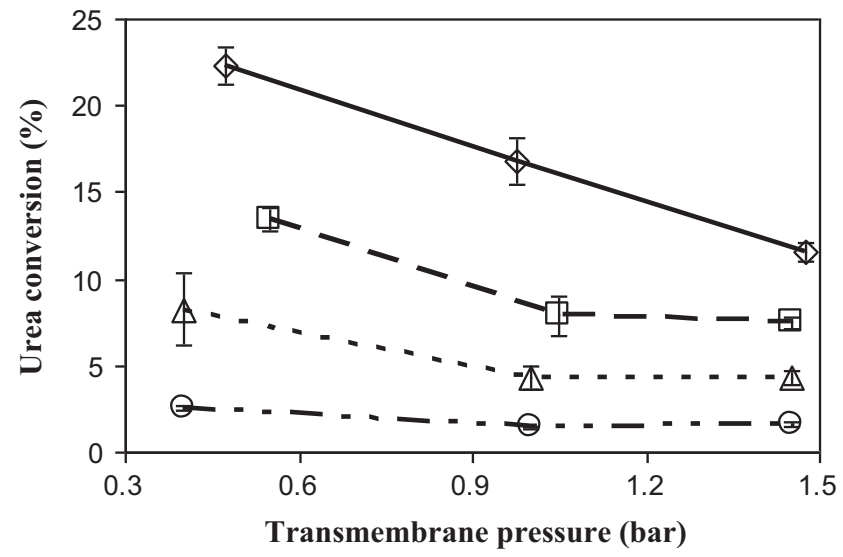

Fig. 13. Percentage of urea conversion through catalytic decomposition of urea by modified AN69 membrane on which urease was chemically immobilized. Feed solution concentrations are $(\diamond) 0.5 \mathrm{mM},(\square) 5.0 \mathrm{mM},(\triangle) 10 \mathrm{mM}$ and $(\bigcirc) 50 \mathrm{mM}$.

increasing transmembrane pressure and urea concentration in the feed solution. This simply indicates that even at the maximum feed concentration the maximum reaction rate has not been achieved. Consequently, it can be said that the filtration process is reaction controlled. This is also confirmed by the decrease in urea conversion with the transmembrane pressure. Since the enzyme is not saturated, the increase in the transmembrane pressure results in a reduced contact time between the substrate and the enzyme, hence, reduced urea conversion. According to the results, maximum urea conversion (22\%) was attained at the lowest feed concentration and the lowest transmembrane pressure.

Kinetic parameters of the immobilized urease under dynamic conditions were also determined by measuring the ammonia contents in permeate and retentate solutions at the end of $10 \mathrm{~min}$ of filtration and they are tabulated in Table 2 . The maximum reaction rate slightly increased with the increasing pressure. These values nearly 4 times lower than those determined from static measurements. This is due to lower temperature in the case of dynamic ultrafiltration experiments. On the other hand, when the reaction rate obtained from static experiments are recalculated at the filtration temperature using Arrhenius equation, we obtained the rate as $2.47 \mu \mathrm{mol} / \mathrm{min} \mathrm{mg}$. The result indicates that the maximum reaction rate of urease immobilized membrane under dynamic conditions is enhanced which might be due to acceleration of mass transfer with continuous permeation of substrate through the membrane. Similar results have also been reported in the literature $[43,44]$.

The influence of mass transfer on the overall filtration process and on the kinetic parameters was determined by calculating the effectiveness factor and Damköhler numbers for each feed concentration and transmembrane pressure applied. The results are listed in Table 3. Small $D_{\mathrm{a}}$ numbers and the effectiveness factors mostly close to 1 indicate that mass transfer effects are negligible and the filtration process is mainly controlled by reaction. This is in accordance with the results illustrated in Fig. 13.

The performance of the prepared membranes was also tested by measuring their residual catalytic activities. It was found that the

Table 2

Kinetic parameters as a function of transmembrane pressure.

\begin{tabular}{lll}
\hline$\Delta P$ (bar) & $V_{\max }(\mu \mathrm{mol} / \mathrm{min} \mathrm{mg})$ & $K_{\mathrm{m}}(\mathrm{mM})$ \\
\hline $0.45 \pm 0.1$ & 2.95 & 2.47 \\
$1.00 \pm 0.1$ & 3.31 & 2.06 \\
$1.45 \pm 0.1$ & 3.52 & 3.00 \\
\hline
\end{tabular}


Table 3

Variation of effectiveness factor with respect to feed concentration and operating pressures.

\begin{tabular}{lcll}
\hline$\Delta P$ (bar) & {$[\mathrm{S}](\mathrm{mM})$} & $\eta$ & $D_{\mathrm{a}}$ \\
\hline 0.475 & 0.5 & 0.16 & 6.33 \\
0.550 & 5 & 0.92 & 0.63 \\
0.400 & 10 & 0.99 & 0.32 \\
0.400 & 50 & 1.00 & 0.06 \\
0.975 & 0.5 & 0.15 & 7.27 \\
1.050 & 5 & 0.92 & 0.73 \\
1.000 & 10 & 0.99 & 0.36 \\
1.000 & 50 & 1.00 & 0.07 \\
1.475 & 0.5 & 0.13 & 7.81 \\
1.450 & 5 & 0.87 & 0.78 \\
1.450 & 10 & 0.97 & 0.39 \\
1.450 & 50 & 1.00 & 0.08 \\
\hline
\end{tabular}

activity of the membrane did not change at the end of $450 \mathrm{~min}$ of filtration.

\section{Conclusion}

In this study, urease was chemically immobilized onto commercial AN69 membrane by means of EDC/NHS coupling agent. Rapid adsorption occurred onto membrane surface, however, due to steric effects between enzyme-enzyme molecules, a stable catalytic membrane was obtained at the end of $24 \mathrm{~h}$ of immobilization. The results obtained with static conditions revealed that urease is thermally stable at higher temperature when it is in immobilized form. Although the kinetic parameters of immobilized urease are slightly less favourable than those of free urease, immobilization preserves the stability of urease at a prolonged time. The hydraulic permeabilities were not influenced from the addition of urease layer or urea concentration in the feed solution. Both results indicate the absence of concentration polarization over the membrane surface. The influence of mass transfer on the overall filtration process was found negligible, hence, the process is reaction-controlled. In addition, a preliminary study indicates that the activity of the membrane can be preserved for almost $8 \mathrm{~h}$. Further studies are required to test the catalytic activity of the membrane over longer operating times. In conclusion, the results obtained in this study suggest that urease immobilized AN69 membrane can be a promising material to be used in ultrafiltration units under pressure for efficient removal of urea from various sources.

\section{Acknowledgment}

The authors would like to thank the Gambro-Hospal, Lyon, France, for kindly providing the AN69 membranes.

\section{References}

[1] B. Krajewska, J. Mol. Catal. B: Enzym. 59 (2009) 22-40.

[2] W. Simka, J. Piotrowski, Przem. Chem. 86 (2007) 841-845.

[3] H.D. Lehmann, R. Marten, C.A. Gullberg, Artif. Organs 5 (1981) 278-285.

[4] D. Lefier, Bull. Int. Dairy Fed 315 (1996) 35.

[5] S. Kodama, T.J. Suzuki, Food Sci. 60 (1995) 1097.

[6] R.L. Blakeley, B. Zerner, J. Mol. Catal. 23 (1984) 263-292.

[7] B. Krajewska, J. Mol. Catal. B: Enzym. 59 (2009) 9-21.

[8] C.C. Lin, M.C. Yang, Biomaterials 24 (2003) 1989-1994.

[9] M.C. Yang, C.C. Lin, Biomaterials 22 (2001) 891-896.

[10] T. Godjevargova, K. Gabrovska, J. Biotechnol. 103 (2003) 107-111.

[11] K. Gabrovska, A. Georgieva, T. Godjevargova, O. Stoilova, N. Manolova, J. Biotechnol. 129 (2007) 674-680.

[12] M.J.B. Wissink, R. Beernink, J.S. Pieper, A.A. Poot, G.H.M. Engbers, T. Beugeling, W.G. Aken, J. Feijen, Biomaterials 22 (2001) 151-163.

[13] M.J.A. van Luyn, P.B. van Wachem, L.H.H. Olde Damink, P.J. Dijkstra, J. Feijen, J. Biomed. Mater. Res. 26 (1992) 1091-1110.

[14] P.B. van Wachem, M.J.A. van Luyn, L.H.H. Olde Damink, P.J. Dijkstra, J. Feijen, P. Nieuwenhuis, Biomaterials 17 (1994) 230-239.

[15] P.B. van Wachem, M.J.A. van Luyn, L.H.H. Olde Damink, P.J. Dijkstra, P. Nieuwenhuis, J. Biomed. Material. Res. 28 (1994) 353-363.

[16] V. Rajesh, W. Bisht, K. Takashima, Kaneto, Biomaterials 26 (2005) 36833690.

[17] F. Kuralay, H. Ozyoruk, A. Yıldız, Sens. Actuators B 114 (2006) 500-506.

[18] S. Komaba, M. Seyama, T. Momma, T. Osaka, Electrochim. Acta 42 (1997) 383-388.

[19] M. Battiloti, C. Colapicchioni, I. Giannini, F. Porceilli, L. Campanella, M. Cordatore, F. Mazzei, M. Tomassetti, Anal. Chim. Acta 221 (1989) 157-161.

[20] R. Konck, T. Lenarczuk, A. Radomska, S. Glab, Analyst 126 (2001) 10801085.

[21] C. Stamm, K. Seiler, W. Simon, Anal. Chim. Acta 282 (1993) 229-237.

[22] S. Guedidi, Y. Yurekli, A. Deratani, P. Déjardin, C. Innocent, S.A. Altinkaya, S. Roudesli, A. Yemenicioglu, J. Membr. Sci. 365 (2010) 59-67.

[23] L.J. Langsdorf, A.L. Zydney, J. Biomed. Mat. Res. 28 (1994) 573-584.

[24] M.W. Weatherburn, Anal. Chem. 39 (1967) 971-974.

[25] M. Bradford, Anal. Biochem. 72 (1976) 248-254.

[26] Z.P. Zhao, Z. Wang, S.C. Wang, J. Membr. Sci. 217 (2003) 151-158.

[27] K.L. Jones, C.R. O'Melia, J. Membr. Sci. 165 (2000) 31-46.

[28] K.A. Smith, C.K. Colton, E.W. Merril, L.B. Evans, Chem. Eng. Progr. Symp. Ser. 64 (1968) 45.

[29] H. Komiyama, J.M. Smith, AIChE J. 20 (1974) 1110-1117.

[30] C.J. Geankoplis, Transport Processes and Unit Operations, 3rd ed., Prentice-Hall International Inc., 1993, pp. 401-402.

[31] C.J. Geankoplis, M.R. Okos, E.A. Grulke, J. Chem. Eng. Data 23 (1978) 40.

[32] W.M. Deen, AIChE. J. 33 (1987) 1409-1425.

[33] W.R. Bowen, A.W. Mohammad, N. Hilal, J. Membr. Sci. 126 (1997) 91-105.

[34] E.J. Herrero, P. Fernandez, J. Turnay, N. Olma, P. Calero, R. Garcia, I. Freile, J.L.C. Olivares, Biomaterials 20 (1999) 539-545.

[35] R.F. Lafuente, V. Rodriguez, C. Mateo, G. Penzol, O.H. Justiz, G. Irazoqui, A. Villarino, K. Ovsejevi, F. Batista, J.M. Guisan, J. Mol. Catal. B: Enzym. 7 (1999) 181-189.

[36] W.C. Lin, T.Y. Liu, M.C. Yang, Biomaterials 25 (2004) 1947-1957.

[37] T.Y. Liu, W.C. Lin, L.Y. Huang, S.Y. Chen, M.C. Yang, Biomaterials 26 (2005) 1437-1444.

[38] P. Ye, Z.K. Xu, J. Wu, C. Innocent, P. Seta, Biomaterials 27 (2006) 4169-4176

[39] F.C. Kung, M.C. Yang, Polym. Adv. Technol. 17 (2006) 419-425.

[40] B. Krajewska, Z. Piwowarska, Biocatal. Biotransform. 23 (2005) 225-232.

[41] J.P. Chen, S.H. Chiu, Enzyme Microb. Technol. 26 (2000) 359-367.

[42] T. Miyata, A. Jikihara, K. Nakamae, J. Appl. Polym. Sci. 63 (1997) 1579-1588.

[43] T. Godjevargova, K. Gabrovska, Macromol. Biosci. 5 (2005) 459-466.

[44] M. Ulbright, A. Papra, Enzyme Microb. Technol. 20 (1997) 61-68. 